\title{
Assessment of Water Supply and Sanitation in Dewanpur Village, Chittagong
}

\author{
Mohd. Mostakim Ali, Panini Amin Chowdhury \\ Department of Urban \& Regional Planning, Chittagong University of Engineering \& Technology, \\ Chittagong, Bangladesh \\ Email: mostakim1992@ymail.com, chowdhurypanini@gmail.com
}

Received 25 October 2014; revised 21 November 2014; accepted 17 December 2014

Copyright @ 2014 by authors and Scientific Research Publishing Inc.

This work is licensed under the Creative Commons Attribution International License (CC BY).

http://creativecommons.org/licenses/by/4.0/

(c) (i) Open Access

\section{Abstract}

Water supply and sanitation are two important sectors in preparing a development plan in an area. Access to water supply and sanitation are basic human needs and rights. Worldwide, $71 \%$ of the rural population has access to improved water supply and $38 \%$ has access to improved sanitation. Bangladesh faces multiple challenges in the sanitation, hygiene and water sectors. According to the Joint Monitoring Report (WHO \& UNICEF, 2012), latrine coverage stood at $56 \%$ by 2012, while the proportion of the population with access to safe water was about $81 \%$. Moreover, in spite of concerted efforts to provide safe water, it is estimated that 25 to 30 million people are affected by arsenic contamination in drinking water. The main objective of this study was to assess the water supply and sanitation situation in the village of Dewanpur, a rural village in Chittagong, Bangladesh. By conducting an assessment one can determine water supply and sanitation coverage of this area and identify water supply and sanitation problems in the village and then propose solutions to improve water supply and sanitation coverage. This paper states the same purpose here.

\section{Keywords}

Sanitation, Water Supply System, Survey Based Analysis, Daily Activity Schedule, Pair Wise Seasonal Ranking

\section{Background of the Study}

Bangladesh is an agricultural country. It has a land of 147,570 square kilometers among which $6.4 \%$ is water. It has 146,888 million populations and the population density is about 1033.5/ $\mathrm{km}^{2}$ (Bangladesh Bureau of Statistics). Most of the people of this country live in villages. About $70 \%$ of the total people of this country live in ru- 
ral areas according to World Bank report published in 2012. The global commitment of Johannesburg declaration 2002 is to achieve 50\% sanitation facilities coverage by 2015 (BBS, 2011). Government of Bangladesh declared the target of achieving a state whereby every household in the nation would have a sanitary latrine by 2010. The target would be fulfilled in three phases by 2005, 2008 and 2010 (DPHE, 2010). But it is not succeeded completely. Water and sanitation are two most important elements which are crucial for economic and social development including energy production, agriculture, domestic and industrial use. Access to safe drinking water and adequate water supplies for hygiene and better sanitation continues to be a challenge for much of the world's population. Many governments and non-governmental organizations are working to expand access to safe and potable water. There are so many factors to consider beyond the initial implementation of a water supply system, including regular maintenance, repairs and replacement. It is important to train local communities and organizations to do need maintenance and expansion work (Ahmed \& Rahman, 2000). This study focuses on the water supply and sanitation process in the dewanpur village in Raojanunion, Chittagong and proposes some alternatives regarding the problems.

\subsection{Objective}

The objective of this study is to analyze the overall water supply and sanitation condition of dewanpur village and propose some alternative solutions.

\subsection{Scope of the Study}

The scope of this study is immense. This study will be helpful at decision making level. It would provide proper guidelines for sustainable water supply and sanitation system. It would be helpful for sustainable development. It would be helpful to minimize system loss and its management level problems. It will also help to make future projection on demand and supply. This study identifies the existing coverage of supply network and indicates the areas outside the supply network. The sanitation condition and situation will help to understand the future need and help to fix up future strategy for this area.

\subsection{Study Area}

"Dewanpur" village is situated in Pahartali union under Raojanupazilla of Chittagong district. Raozan Upazila is located at $22.5333^{\circ} \mathrm{N} 91.9333^{\circ} \mathrm{E}$. The number of units of house hold is 1068 and total area is 995 acre in this union. Two main rivers which are flowing on Raozan Upazila are Karnaphuli and Halda. Raozan is surrounded by Fatikchhari Upazila on the north, Boalkhali Upazila and Karnafuli River on the south, Rangunia and Kawkhali (Rangamati) Upazilas on the east, Hathazari and Fatikchhari Upazila on the west. The study area Dewanpur village is located in north-east side of Chittagong city. Noakhalikhal is situated at south part of this village and has separated the village from the village "Gahchi", Pahartali \& khaiyakhali village. This canal is the main source of water for irrigation. The population density of the study area is 3 persons per acre. The literacy rate of Dewanpur village is $69.33 \%$ in an average (BBS Census Report, 2011).

\section{Methodology}

As it is a social problem related topic the whole project is conducted from the questionnaire survey based findings. For these $5 \%$ of the population that mean's 70 respondents are selected for the questionnaire. For secondary data, BBS, Raojan unionparishad and also the union parishad office were visited and relevant data were collected. For analysis SPSS and MS excel software is used for overall data processing and analysis. For discussion pair wise seasonal ranking, cause effect table and daily schedule wise water and sanitary latrine demand has been analyzed.

\section{Findings}

\subsection{Water Supply}

From the overall water supply analysis it is found that $88.57 \%$ of the respondents use tubes well as their drinking water source while $8.57 \%$ of them use pond or river and rest use other sources for drinking water. Almost $82.86 \%$ of the respondent's houses have tubewell facilities while rests of them have to depend on their neigh- 
bor's house tubewell. About 78.57\% tubewell are free from arsenic. 15.71\% tube wells are contaminated with arsenic but many of this tube wells are not use for drinking water. The water of pond and river is not polluted. Chittagong region especially in the Dewanpur village, there no problem to get water by tube well throughout the year. Again the pond and river does not dry at any season. 97.14\% people get water in their tube well or pond throughout the year. Maximum people drink water without treatment. Among 70 people only 8 person (11.4\%) drink boiling water and 13 people (18.6\%) drink water by filtering. As they drink tube well water so they do not take any treatment process to clean the water.

\subsection{Sanitation System}

Among 70 respondents 54 people (77.1\%) use covered or sanitary latrine. 6 houses use uncovered latrine, 6 houses use septic tank and only 4 houses (5.7\%) does not have any toilet facilities. 32.9\% of the village people use latrine which cost is between 1000 to 2500. And about 22.9\% people use latrine which cost is between 2500 to 3500. So we can say that people of this area use low cost sanitary latrine. People of Dewanpur village use tin as construction of the rope and many of them use pacca construction base. Here about 32 people among 70 use tin as the rope construction and 41 people use brick or cement as the base of the latrine. About 48 people (73.8\%) are satisfied with their latrine and 26.2\% people are not with their latrine. Among the respondents, people use covered dry latrine well saved from diseases as 25 respondents are found has no problem in water diseases. While the ratio of water related diseases are relatively high in uncovered latrine. But the most effective method is flush septic tank where almost no disease affected people are found. Again the people who do not have any facilities are affected most. Wife or the daughter of the family is responsible for the maintenance of latrine. The people of Dewanpur village usually use private latrine. As the sanitation rate is almost $80 \%$ so we can say the people of Dewanpur village lead a standard life.

\section{Discussions}

From the findings it can be said that the water supply and sanitation situation of this village is not dissatisfactory. But People of this locality do not make any treatment of water. So they have to motivate to that they purify their drinking water. Water of this locality is polluted by agricultural activities. So some steps should be taken to stop the water pollution. But a good sign is that majority of the tube wells are free from arsenic pollution. Water availability is also not a big issue for this region. Ground water is still available in this locality but the iron rate in the water is a bit high. Again the rate of tube Wells affected by arsenic is also increasing alarmingly. So overall water supply situation is not bad at all. But facilities and door to door water supply system is yet to develop and should a concern of the authority in their future development strategy. The sanitation rate of the village is almost 80\%. But many people do not have any sanitary latrine. People here mainly rely on the low cost indigenous materials for their construction of the latrines .So government training on this sector is necessary. Waterborne disease rate is also not in an epidemic form. Now a daily schedule of daily water supply and sanitation based activities are given in Table 1.

From the figure it is quite clear that water availability is not a big issue for this area. It is available all through the day. But during the morning and noon period people need to wait a bit for collecting water because on the morning time everyone is busy to go to their working and related places. So all of them need to take bath and other morning activities at a very close time. At the noon period after completing lunch people need water for washing their dishes. Some also wash their clothes during this period. Because of the morning rush they also have to wait in the toilet too. As water use is very high in the morning and noon period that's why its demand is also high during that period. The demand for toilet also supports the demand for water also (Table 2).

From the pair wise seasonal ranking it is found that water is slightly unavailable on the April to July period as it is the summer time. The quality of water also deteriorates a bit in this period. Otherwise rest of the period it is quite available and the quality also is good. Because of the hot, humid summer period the demand for water also increases a bit in the April to July period. Because of the unavailability of water during this period the condition of the toilet is also not satisfactory. Diseases like diarrhea, dysentery, typhoid etc. also increase a lot during this period. Otherwise rest of the period the condition of this village is quite peaceful (Table 3).

This cause effect table states that the main problem of water supply of this village is arsenic contamination and Iron. For these two the water quality deteriorates which make the water unable to drink and also create waterborne diseases. In the sanitation sector the main issue is low cost sanitary latrines. So in a very quick period 
Table 1. Daily activity schedule: water and sanitation.

\begin{tabular}{|c|c|c|c|c|c|c|}
\hline Criteria & $7.00 \mathrm{am}-8.00 \mathrm{am}$ & 9 am - 12 pm & $1 \mathrm{pm}-2 \mathrm{pm}$ & 3 pm - 6 pm & 7 pm - 8 pm & $8 p m-10 p m$ \\
\hline Availability of water & Available & Available & Available & Available & Available & Available \\
\hline Waiting time for water & $\begin{array}{l}\text { Have to wait } \\
(10-15 \text { min })\end{array}$ & No waiting & $\begin{array}{l}\text { Have to wait } \\
(10-15 \text { min })\end{array}$ & No waiting & No waiting & No waiting \\
\hline Waiting time for toilet & $10 \mathrm{~min}$ & $7-12 \min$ & $0 \min$ & $0 \mathrm{~min}$ & $4-5 \min$ & $4-5 \min$ \\
\hline Demand for water & 6 - 8 liter & 4 - 5 liter & 8 - 10 liter & 5 - 6 liter & 5 - 7 liter & 1 - 2 liter \\
\hline Demand for toilet & $\begin{array}{l}3 \text { people } \\
\text { at a time }\end{array}$ & $\begin{array}{l}1 \text { people } \\
\text { at a time }\end{array}$ & $\begin{array}{l}3 \text { people } \\
\text { at a time }\end{array}$ & $\begin{array}{l}1 \text { people } \\
\text { at a time }\end{array}$ & $\begin{array}{l}2 \text { people } \\
\text { at a time }\end{array}$ & $\begin{array}{l}1 \text { people } \\
\text { at a time }\end{array}$ \\
\hline
\end{tabular}

Table 2. Pair wise seasonal ranking.

\begin{tabular}{|c|c|c|c|c|c|c|c|c|c|c|c|c|}
\hline Criteria & Jan & Feb & Mar & Apr. & May & June & July & August & Sep. & Oct. & Nov. & Dec. \\
\hline Availability of water & & Moderate & & \multicolumn{4}{|c|}{ Low } & \multicolumn{5}{|c|}{ High } \\
\hline Quality of water & & & Good & & & & Bad & & \multicolumn{4}{|c|}{ Good } \\
\hline Water demand & & Moderate & & & & & & \multicolumn{5}{|c|}{ Moderate } \\
\hline Condition of toilet & & Moderate & & & Filthy & Bad & & \multicolumn{5}{|c|}{ Moderate } \\
\hline Disease & & Low & & \multicolumn{3}{|c|}{ High } & & \multicolumn{5}{|c|}{ Low } \\
\hline
\end{tabular}

Table 3. Cause effect table.

\begin{tabular}{ccc}
\hline Factors & Water supply & Sanitation \\
\hline Effects & Unable to drink \& waterborne diseases & Difficulties in using toilets \\
Problem & Deterioration of water quality & Filthy condition \\
Cause & Arsenic contamination \& Iron & Low cost sanitary latrines \\
\hline
\end{tabular}

of time it decrease from its standard which create difficulties in using the toilet.

To ensure proper sanitation for every person and to achieve MDG goals it is required to make some project on sanitation in this village. Many people do not wash their hand after toilet. It is really harmful for their health.

\subsection{Solution}

Some solutions are proposed here in respect of the problems that are found in this village.

\section{Water supply}

\section{1) Arsenic Contamination}

a) Improved Dug Well: Improved dug wells with the introduction of flexible pipes with float.

b) Surface Water Treatment

c) Pond Sand Filter: Treatment of surface water with slow sand filtration, popularly known as Pond Sand Filter (PSF)/River Sand Filter (RSF), shall be considered a suitable alternative water supply option for this area (WHO \& UNICEF, 2012).

d) Deep Hand Tube Well: It can also be an important way.

e) Rainwater Harvesting: Rainwater harvesting is basically a household-based technology. It has good potential for water supply all over the country.

f) Arsenic Removal Technology: These technology options fall in to two main groups-household and community level (Water Policy, 2003).

2) Iron Contamination: Iron filtration through strainer is a good option to remove iron from the water. Different chemicals can also be used. 


\subsection{Sanitation}

The main sanitation problem of this locality was low graded less durable sanitary latrine. For this:

- DPHE (Department of Public health \& Education) can take action on this case.

- Different NGO's can provide standard sanitary system to the people.

- Shops can sell these equipment's in installment.

- Public awareness development is an important factor on this.

\section{Conclusion}

For a healthy living condition of this village, it is needed to supply water and provide sanitation facilities in every classes of population to ensure their good health and also to improve the standard of their life. Proper sanitation and water supply will also improve the environmental quality of the village. People of every sector should be integrated with safe water development process and every family should be motivated. And it needs the integration of social power and combined effort. To sustain this condition and accelerate the scenario, some short, mid and long term plan is very much necessary. Government and other organizations can play a key role in this respect.

\section{References}

Ahmed, M. F., \& Rahman, M. M. (2000). Water Supply and Sanitation, Rural and Low income Urban Communities. Dhaka: ITN-Bangladesh.

BBS Census Report, 2011. http://www.sid.gov.bd/wp-content/uploads/2014/01/Socio_Economic.pdf

Department of Public Health Engineering Report, 2010. http://dphe.gov.bd/index.php?option=com_content\&view=article\&id=71\&Itemid=80

Joint Monitoring Report on Bangladesh, WHO \& UNICEF, 2012.

Water Policy 2003. http://users.physics.harvard.edu/ wilson/arsenic/countries/bangladesh/National\%20Water\%20Policy\%202003/Arsenic\%2 0IMPLEM\%20FINAL-23-8-03.pdf 
Scientific Research Publishing (SCIRP) is one of the largest Open Access journal publishers. It is currently publishing more than 200 open access, online, peer-reviewed journals covering a wide range of academic disciplines. SCIRP serves the worldwide academic communities and contributes to the progress and application of science with its publication.

Other selected journals from SCIRP are listed as below. Submit your manuscript to us via either submit@scirp.org or Online Submission Portal.
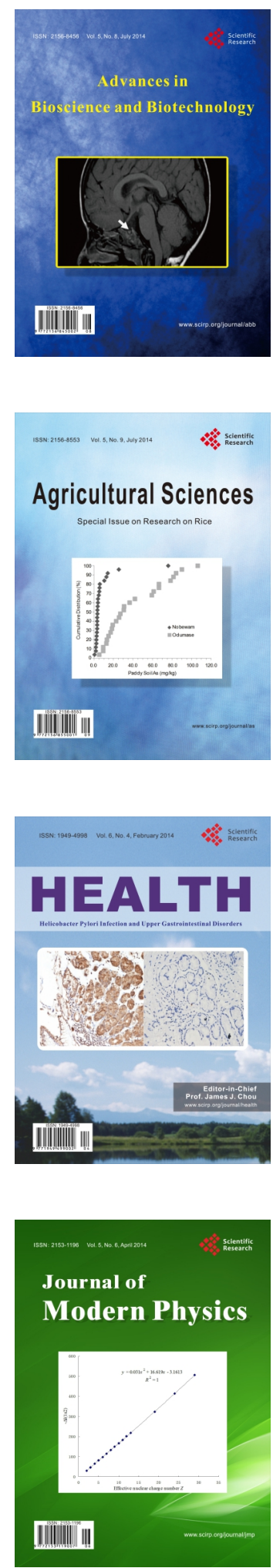
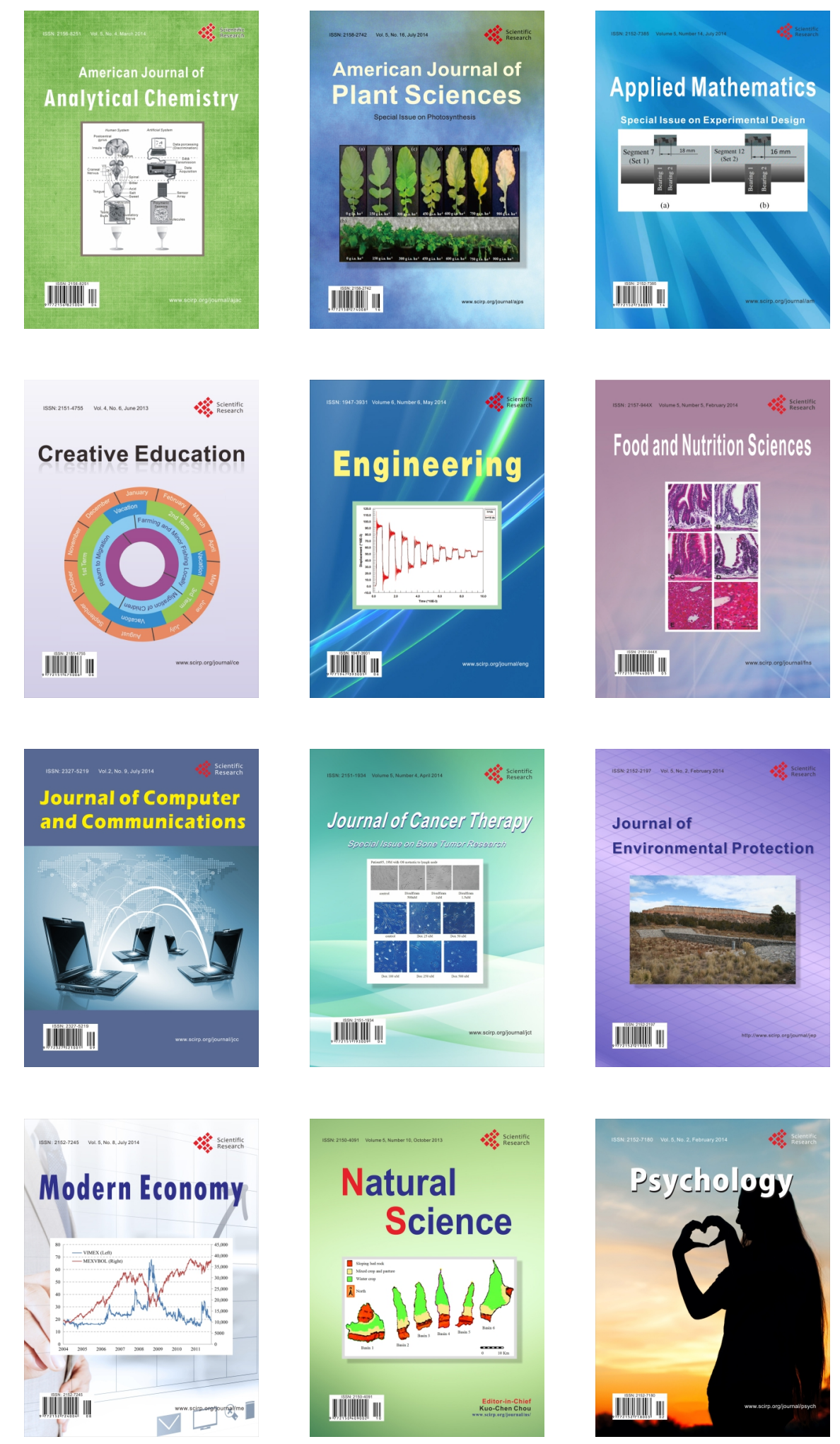